\title{
People with Down's syndrome can be distinguished on the basis of cholinergic dysfunction
}

\author{
BEN SACKS,* STEPHEN SMITH** \\ From the Department of Psychiatry, ${ }^{*}$ Charing Cross and Westminster Medical School, London, and Division of \\ Pharmacological Sciences and Toxicology, ${ }^{* *}$ United Medical and Dental Schools of Guy's and St Thomas's \\ Hospitals, London
}

SUMMARY The mydriatic response to eyedrops of the anticholinergic agent tropicamide at very low concentration $(0.01 \%)$ has been studied in people with Down's syndrome. By comparison with healthy subjects people with Down's syndrome had responses approximately three times greater, suggesting a peripheral imbalance between cholinergic and adrenergic autonomic influences.

The characteristic histology of dementia of the Alzheimer's type (DAT) is found in all people with Down's syndrome (DS) over the age of 30 years. ${ }^{1}$ The occurrence of plaques and tangles, which are the basis of the diagnosis in DAT, develop 20 to 30 years earlier in DS and dementia is clinically detected at least three times more frequently than in a control population. ${ }^{1}$ The hallmark of the neurotransmitter abnormalities in DAT is a deficit in the cholinergic system of the brain ${ }^{23}$ and defects of cholinergic transmission are associated with memory disorders. ${ }^{46}$ People with DS seem to have a memory deficit ${ }^{6}$ which is not associated with dementia and they also show supersensitivity to atropine, both in cardiac ${ }^{7}$ and pupillary responses. ${ }^{8-10}$ We report a simple eyedrop test which shows cholinergic dysfunction in people with DS to an extent which distinguishes them from normal controls.

\section{Methods}

We studied thirteen subjects with Down's syndrome (6 male, 7 female) aged 12 to 50 and twelve healthy subjects ( 2 male, 10 female) aged 14 to 58 . None was receiving medication. Tropicamide eyedrops $0.01 \%$ were freshly made up in

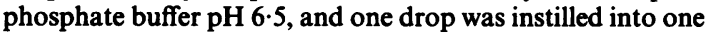
conjunctival sac. The concentration was chosen after preliminary studies revealed a minimal response in healthy

Correspondence to: Professor B Sacks, Unit of Mental Handicap, 24 St Dunstan's Road, London W6 8RP, United Kingdom.

Received 13 January 1989 and in revised form 19 April 1989. Accepted 9 June 1989 subjects. Pupil diameters were measured photographically under standard lighting conditions and expressed as the ratio pupil/iris diameter." Drug effects were recorded at 20, 30-35 and 45-60 minutes after instillation as the ratio difference between treated and untreated eyes corrected for any pretreatment discrepancy.

Differences between the responses of the two groups of subjects at each time point were assessed by Student $t$-tests.

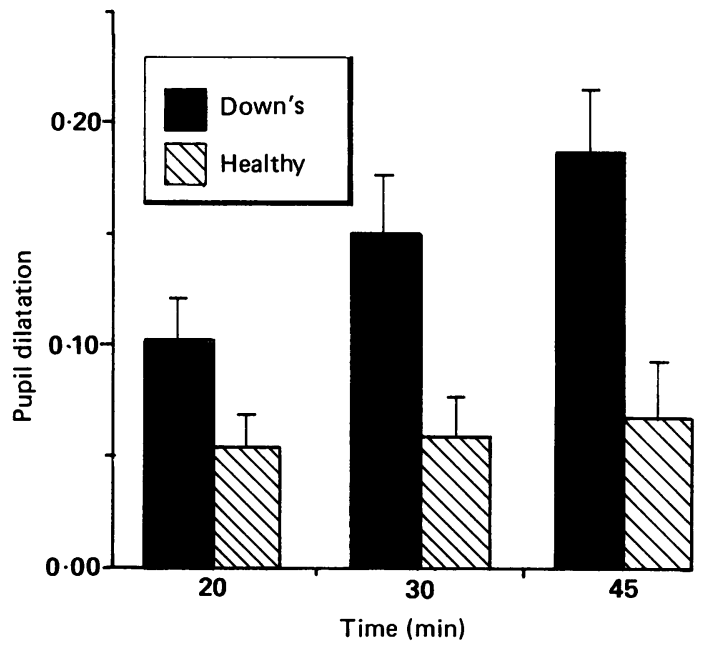

Figure Mydriatic responses mean (SEM) of those with Down's syndrome and healthy subjects following instillation of tropicamide $0.01 \%$. Pupil dilatation = increase in pupil/ iris diameter ratio. 


\section{Results}

Pupil responses to tropicamide are shown in the figure. Those of the patients exceeded those of the healthy subjects at $20 \mathrm{~min}$ (1.91-fold; $\mathrm{p}<0.05), 30-35 \mathrm{~min}$ (2.54-fold; $\mathrm{p}<0.01)$ and $45-60 \mathrm{~min}$ (2.75-fold; $\mathrm{p}<0.05)$. The responses were unaffected by age. They appeared to be greater in subjects with blue and hazel eyes than those with brown eyes, but there were too few of the latter to permit statistical evaluation.

\section{Discussion}

The supersensitivity to the anticholinoceptor drug tropicamide shown by patients with Down's syndrome is consistent with the hypothesis that there is reduced cholinergic drive in this condition. The results should, however, be interpreted with caution as we cannot be certain that penetration of the drug through the cornea is the same in these patients as in healthy subjects. Although we observed blepharitis in some of the patients, there was no obvious corneal or scleral abnormality. It is unlikely therefore that exaggerated drug permeability could account for the difference in response.

This procedure allows for the distinction between those with DS and normal controls on the basis of difference in cholinergic function. Since people with DAT appear to show behavioural and cognitive sensitivity to hyoscine, ${ }^{12}$ this eyedrop test could be used to distinguish people with DAT from those with other forms of dementia. If this proves possible, then the test might function as a marker for DAT in life as the definitive diagnosis, at present, can only be made at necropsy.

\section{References}

1 Wisniewski KE, Wisniewski HM, Wen GY. Occurrence of neuropathological changes and dementia of Alzheimer's disease in Down's Syndrome. Ann Neurol 1985;17:278-82.

2 Rossor MN, Iversen LL, Reynolds GP, Mountjoy CQ, Roth M. Neurochemical characteristics of early and late onset types of Alzheimer's disease. $\mathrm{Br} \mathrm{Med} J$ 1984;288:961-4.

3 Sims NR, Bowen DM, Allen SJ, et al. Presynaptic cholinergic dysfunction in patients with dementia. $J$ Neurochem 1983;40:503-9.

4 Francis PT, Palmer DM, Sims NR, et al. Neurochemical studies of early-onset Alzheimer's disease-possible influence on treatment. $N$ Engl J Med 1985;313:7-11.

5 Arendt T, Allen Y, Sinden J, et al. Cholinergic-rich brain transplants reverse alcoholic-induced memory deficits. Nature 1988;332:448-50.

6 McDade HL, Adler S. Down's Syndrome and short-term memory impairment: a storage or retrieval deficit. $\mathrm{Am} \mathrm{J}$ Men Defic 1980;84:561-7.

7 Harris WS, Goodman RM. Hyper-reactivity to atropine in Down's Syndrome. $N$ Engl J Med 1968;279:407-10.

8 Berg JM, Brandon MWG, Kirman BH. Atropine in Mongolism. Lancet 1959;ii:441-2.

9 Priest JH. Atropine response of the eyes in Mongolism. Am J Dis Child 1960;100:869-72.

10 O'Brien D, Haake MW, Braid B. Atropine sensitivity and serotonin in Mongolism. Am J Dis Child 1960;100: 873-4.

11 Smith SA, Dewhirst RR. A simple diagnostic test for pupillary abnormality in diabetic autonomic neuropathy. Diabet Med 1986;3:38-41.

12 Sunderland T, Tariot PN, Cohen RM, Weingartner H, Mueller III EA, Murphy DL. Anticholinergic sensitivity in patients with dementia of the Alzheimer type and agematched controls. Arch Gen Psychiat 1987;44:418-26. 